\title{
DOES CONTRARY-FORMING PREDICATE NEGATION SOLVE THE NEGATION PROBLEM?
}

\author{
Robert Mabrito
}

$\square^{t}$ OLVING EXPRESSIVISM's Frege-Geach problem requires specifying the attitudes expressed by arbitrarily complex moral sentences. Nicholas Unwin emphasizes the problems that arise in doing so for even the relatively simple case of negated atomic sentences. ${ }^{1}$ Terry Horgan and Mark Timmons believe that contrary-forming predicate negation offers a solution to this negation problem. ${ }^{2}$ I argue that their solution is incomplete.

\section{THE NEGATION PROBLEM}

Consider Marie, who is contemplating the morality of stealing. One possibility is that

w: Marie thinks that stealing is wrong.

Following Horgan and Timmons, assume that expressivists take it that for Marie to think that stealing is wrong is for her to oppose stealing. ${ }^{3}$ As Unwin points out, expressivists have a problem accounting for all the possible views Marie might have. To illustrate Unwin's point, consider the following:

\section{Marie's View}

N Marie does not think that stealing is wrong.

W Marie thinks that not stealing is wrong.

$\sim$ W Marie thinks that stealing is not wrong.
Expressivist Interpretation

Marie does not oppose stealing.

Marie opposes not stealing.

1 Unwin, "Quasi-Realism, Negation, and the Frege-Geach Problem."

2 Horgan and Timmons, "Expressivism and Contrary-Forming Negation."

3 Horgan and Timmons, "Expressivism and Contrary-Forming Negation," 98. 
The negation problem is the problem of specifying-according to expressivism - what it is for Marie to think that stealing is not wrong. Given the reasonable assumption that Marie's state of mind in $\sim \mathrm{W}$ is distinct from her state in either $\mathrm{W} \sim$ or $\mathrm{N}$, expressivists cannot say that in $\sim \mathrm{W}$ Marie opposes not stealing or simply does not oppose stealing. Indeed, as an argument due to Mark Schroeder shows, expressivists cannot take it that in $\sim \mathrm{W}$ Marie's attitude is one of opposition to anything. ${ }^{4}$

Horgan and Timmons attempt to solve this negation problem by distinguishing between two types of negation. ${ }^{5}$ The "not" in

Marie does not oppose stealing.

might express contradictory-forming sentential negation, in which case the above sentence is equivalent to

$\mathrm{SN}$ : It is not the case that Marie opposes stealing.

Or, it might express contrary-forming predicate negation, in which case the sentence is equivalent to

PN: Marie is unopposed to stealing.

For Horgan and Timmons, SN describes Marie's state in $\mathbf{N}$ while PN describes her state in $\sim \mathrm{W}^{6}{ }^{6}$ Of course, Marie's states in $\mathrm{N}$ and $\sim \mathrm{W}$ are distinct if and only if $\mathrm{SN}$ and $\mathrm{PN}$ are not equivalent.

Horgan and Timmons argue that SN and PN are not equivalent because the concept of opposition is trivalent. ${ }^{7}$ Associated with every trivalent concept is a feature and an anti-feature, which are such that everything falls into one of three non-overlapping and non-empty groups: (i) those things with the feature, (ii) those with the anti-feature, and (iii) those with neither. ${ }^{8}$ Thus, while it is impossible to simultaneously possess both an anti-feature and its corresponding feature, it is possible to possess neither. The referent of a term that expresses a trivalent concept is the feature while the anti-feature is the referent of the term produced by applying a prefix such as "un-" or "in-." Horgan and Timmons offer "pleasant" as an example; it picks out a feature while "unpleasant" picks out the relevant anti-feature. ${ }^{9}$ Thus, the contradictory-forming sentential negation of

4 Schroeder, Being For, 45-46.

5 Horgan and Timmons, "Expressivism and Contrary-Forming Negation," 96-97.

6 Horgan and Timmons, "Expressivism and Contrary-Forming Negation," 98.

7 Horgan and Timmons, "Expressivism and Contrary-Forming Negation," 96-98.

8 Horgan and Timmons, "Expressivism and Contrary-Forming Negation," 96.

9 Horgan and Timmons, "Expressivism and Contrary-Forming Negation," 96. 
$\mathrm{P}_{1}: A$ is pleasant

is

$\mathrm{P}_{2}:$ It is not the case that $A$ is pleasant

while the contrary-forming predicate negation is

$\mathrm{P}_{3}: A$ is unpleasant.

The two negations are not equivalent. $\mathrm{P}_{2}$ is just the negative claim that $A$ lacks the relevant feature, while $\mathrm{P}_{3}$ is the positive claim that $A$ possesses the relevant anti-feature.

If the concept of opposition is trivalent, then the term "unopposed" refers to the relevant anti-feature. If so, to be unopposed to stealing is not simply a matter of being not opposed, just like being unpleasant is not simply a matter of being not pleasant. To be unopposed is to possess an attitude that stands to the attitude of opposition as an anti-feature stands to a feature. Thus, SN and PN are not equivalent. SN is just the negative claim that Marie lacks the attitude of opposition while PN is the positive claim that Marie has its anti-feature, i.e., the attitude of unopposition. Thanks to trivalence, the proposal of Horgan and Timmons assigns distinct states to Marie in $\sim \mathrm{W}, \mathrm{W} \sim$, and $\mathrm{N}$.

\section{A COMPLETE SOLUTION?}

In addition to assigning distinct states to Marie in $\sim \mathrm{W}, \mathrm{W} \sim$, and $\mathrm{N}$, any acceptable expressivist solution to the negation problem must entail that Marie's state in $\sim \mathrm{W}$ is inconsistent with her state in $\mathrm{W}$. Horgan and Timmons believe that their solution does so; they say it "provides the resources to explain why it is logically inconsistent to be simultaneously both opposed and unopposed to the same thing." ${ }^{10}$ But it is important to distinguish two claims:

A: An agent simultaneously being both opposed to $x$ and being unopposed to $x$ is a logically inconsistent state of affairs.

B: Being opposed to $x$ is logically inconsistent with being unopposed to $x$ in the way in which a belief that $p$ is logically inconsistent with a belief that $\sim p$.

Say two states are incompatible just in case a claim analogous to A is true of them; an agent cannot simultaneously instantiate two incompatible states. Say two states are inconsistent just in case a claim analogous to $\mathrm{B}$ is true of them; inconsis10 Horgan and Timmons, "Expressivism and Contrary-Forming Negation," 99. 
tent states clash in the way beliefs in inconsistent propositions do. Incompatibility does not entail inconsistency. (I leave it open whether inconsistency entails incompatibility.) Having a headache and not having a headache are incompatible states, but they are not inconsistent. Marie's headache and Angela's lack of a headache are not inconsistent in the way, say, Marie's belief that snow is white and Angela's belief that it is not white are. To borrow Allan Gibbard's way of putting the point, in the headache case there is a difference between Marie and Angela without there being disagreement, while in the belief case there is both. ${ }^{11}$

That the concept of opposition is trivalent entails both that being unopposed is distinct from simply not being opposed and that it is incompatible with being opposed. These two claims follow, by definition, from the fact that unopposition stands to opposition as an anti-feature stands to a feature. But the fact that the concept of opposition is trivalent does not by itself entail that opposition and unopposition are inconsistent. Consider the concept I will call hensitivity. (Compare to James Dreier's example of hiyo or Gibbard's example of yowee. ${ }^{12}$ ) Say one is hensitive toward $x$ just in case one possesses:

$\mathrm{H}$ : the disposition toward developing a headache when exposed to $x$.

There is a disposition that stands to $\mathrm{H}$ as an anti-feature stands to a feature, namely:

$\mathrm{NH}$ : the disposition toward not developing a headache when exposed to $x$.

One cannot possess both dispositions, but one might lack both because one's tendency to develop headaches is unrelated to one's exposure to $x$. Thus, the concept of hensitivity is trivalent. One is hensitive toward $x$ if one possesses the feature $\mathrm{H}$, unhensitive if one possesses its anti-feature $\mathrm{NH}$, and neither if one lacks both. As in the case of opposition, that the concept of hensitivity is trivalent entails that being unhensitive is distinct from not being hensitive and incompatible with being hensitive. But it is not plausible to take it that hensitivity and unhensitivity are inconsistent. If Marie is hensitive toward paint and Angela is unhensitive toward it, we would not want to say that Marie's hensitivity is inconsistent with Angela's unhensitivity in the way in which Marie's belief that snow is white and Angela's belief that it is not white are inconsistent. In Gibbard's terminology, in the hensitivity case there is a difference between Marie and Angela, but they do not appear in virtue of this difference to be disagreeing with each other. The example of hensitivity shows that trivalence does not guarantee inconsistency.

Thus, the fact that the concept of opposition is trivalent only goes so far in

Gibbard, Thinking How to Live, 60-68.

Dreier, "Expressivist Embeddings and Minimalist Truth"; Gibbard, Thinking How to Live, 65. 
solving the negation problem. Establishing trivalence establishes that being unopposed is distinct from simply being not opposed, but it does not establish that it is inconsistent with being opposed. An additional argument is needed to establish this second claim. Of course, the nature of this additional argument depends on how the attitude of unopposition is specified. Horgan and Timmons offer one proposal for doing so, though they allow for the possibility of others. ${ }^{13}$ Their proposal appeals to motivated dispositions, which are dispositions "to behave-in-a-specific-way-for-a-specific-reason." ${ }^{14}$ For Horgan and Timmons, Marie's opposition to stealing constitutively involves her possessing certain motivated dispositions concerning particular acts of stealing, such as

D: the disposition toward [refraining from taking candy from children because doing so is an act of stealing]. ${ }^{15}$

For Marie to be unopposed to stealing involves her constitutively possessing the corresponding negative dispositions, such as

ND: the disposition toward not [refraining from taking candy from children because doing so is an act of stealing].

Note that the fact that Marie possesses ND does not entail that Marie is disposed to take candy from children. According to the account of Horgan and Timmons, Marie can still be disposed to refrain from stealing candy from children so long as she is not disposed to refrain because it is an act of stealing. ${ }^{16}$ She might be disposed to refrain from taking candy from children because it makes them cry. Also note that, while Marie cannot instantiate both D and ND, she might instantiate neither because she has no relevant motivated dispositions. ${ }^{17}$ Thus, Marie cannot be both opposed to and unopposed to stealing, but she might be neither. So understood, the attitude of unopposition stands to the attitude of opposition as an anti-feature stands to a feature.

Given this account, explaining why opposition is inconsistent with unopposition requires explaining, for example, why Marie's disposition $\mathrm{D}$ is inconsistent with, say, Angela's disposition ND in the way in which Marie's belief that $p$ and Angela's belief that $\sim p$ are. If Marie opposes stealing while Angela is unopposed, they have different and incompatible motivated dispositions - such as D and NDbut, in virtue of this, do they count as disagreeing with each other? As the ex-

13 Horgan and Timmons, "Expressivism and Contrary-Forming Negation," 100.

14 Horgan and Timmons, "Expressivism and Contrary-Forming Negation,” 100.

15 Horgan and Timmons, "Expressivism and Contrary-Forming Negation," 101-2.

16 Horgan and Timmons, "Expressivism and Contrary-Forming Negation,” 100.

17 Horgan and Timmons, "Expressivism and Contrary-Forming Negation,” 101. 
ample of hensitivity shows, that the concept of opposition is trivalent does not settle this question. Further argument is needed. For example, expressivists pursuing this line might borrow from Schroeder's proposed solution to the negation problem. It appeals to the notion of an inconsistency-transmitting attitude, where an attitude is inconsistency-transmitting just in case an instance of it directed toward a content $x$ is inconsistent with an instance directed toward an inconsistent content. ${ }^{18}$ Belief is an uncontroversial example of an inconsistency-transmitting attitude. Schroeder thinks expressivists may assume there are other inconsistency-transmitting attitudes. ${ }^{19}$ If $\mathrm{D}$ and ND-which have inconsistent contentsare two instances of an inconsistency-transmitting attitude, then this would explain why opposition and unopposition are inconsistent. Unfortunately, it is not clear that motivated disposition is an inconsistency-transmitting attitude, since, in general, disposition is not, as the discussion of hensitivity demonstrates.

Note that the claim here is not that it is impossible to argue that opposition and unopposition are inconsistent in the relevant sense. (Perhaps motivated disposition is an inconsistency-transmitting attitude even though disposition in general is not.) Rather, the claim is that Horgan and Timmons have failed to provide such an argument. This failure may be due to a failure to distinguish between an agent instantiating an attitude and the attitude itself. For example, the failure to distinguish between the members of the following pairs:

(1) Marie opposes $x$.

(1a) The attitude of opposing $x$

(2) Marie is unopposed toward $x$.

(2a) The attitude of being unopposed toward $x$.

Horgan and Timmons have an explanation of why (1) and (2) are inconsistentnamely, that on their account opposition and unopposition are incompatible. But that explanation is not an explanation of the inconsistency of (1a) and (2a). And Horgan and Timmons need an explanation of that to completely solve the negation problem.

North Carolina State University robert_mabrito@ncsu.edu

19 Schroeder, Being For, 42-44. 


\section{REFERENCES}

Dreier, James. "Expressivist Embeddings and Minimalist Truth." Philosophical Studies 83, no. 1 (July 1996): 29-51.

Gibbard, Allan. Thinking How to Live. Cambridge, MA: Harvard University Press, 2003.

Horgan, Terry, and Mark Timmons. "Expressivism and Contrary-Forming Negation.” Philosophical Issues 19 (2009): 92-112.

Schroeder, Mark. Being For: Evaluating the Semantic Program of Expressivism. Oxford: Oxford University Press, 2008.

Unwin, Nicholas. "Quasi-Realism, Negation, and the Frege-Geach Problem." The Philosophical Quarterly 49, no. 196 (July 1999): 337-52. 